\title{
Livelihood vulnerability assessment to climate variability and change using fuzzy cognitive mapping approach
}

\author{
Pramod K Singh • Abhishek Nair
}

Received: 3 November 2013 / Accepted: 29 September 2014 / Published online: 4 November 2014

(C) The Author(s) 2014. This article is published with open access at Springerlink.com

\begin{abstract}
Existing studies in the context of assessing vulnerability to climate variability and change delineate, rather inadequately, interconnected interactions occurring within the climate-human-environment interaction space. Besides, studies documenting stakeholders' perceptions regarding climate change induced vulnerabilities are limited in terms of providing indicators for decision-making. This paper aims at constructing a livelihood vulnerability index for climate variability and change capturing interconnected interactions based on peoples' perceptions while providing indicators for evidence based decision-making. A semi-quantitative fuzzy cognitive mapping (FCM) approach has been deployed to capture peoples' perceptions of climate induced perturbations and adaptations. This approach helps quantify stakeholders' perspectives while capturing interconnected interactions in order to estimate livelihood vulnerability to climate variability and change of poor agro-pastoralists in the Bhilwara, a district in Western India. Combining the FCM approach with a sustainable livelihood framework warrants an understanding of assets sensitive to climate variability and change along with those serving as adaptive capacities. The findings of this study confirm that financial and natural assets are most susceptible to harm while organisational and financial assets provide resilience against climate variability and change. The results suggest that livelihood vulnerability of agropastoralists lie in the range of being 'vulnerable' to climate variability and change while varying across three seasons summer, winter, and rainfall.
\end{abstract}

\section{Introduction}

Climate change is a long-term and global phenomenon involving complex interactions between climatic, socio-economic, environmental, technological, institutional, and political processes. Livelihoods have been increasingly affected by climate variability and change, Olsson et al. (2014) have affirmed their adverse impacts on people's health and safety, particularly those of poor people in poor countries. Rural populations of the Asia-Pacific region have to deal with land degradation, serious loss of high-value agricultural lands, and reduced crop yields owed to increasing temperatures and varying precipitation patterns (IFAD

P. K. Singh $(\bowtie) \cdot$ A. Nair

Institute of Rural Management, Anand, India

e-mail: pramod@irma.ac.in 
and the Global Mechanism 2009) threatening the agriculture and animal husbandry sectors further affecting lives and livelihoods.

Escalating competition for resources coupled with climate variability and change has been threatening the livelihoods of agro-pastoralists in Rajasthan. Climate change projections for Rajasthan under the A1B SRES scenario for the near-term (2021-2050) suggest an increase in temperature of about $2-2.5^{\circ} \mathrm{C}$ (Gopalakrishnan et al. 2011); mean annual rainfall is expected to decrease and extreme rainfall to increase in both frequency and intensity (SDC V\&A Programme 2009). Understanding the dynamic nature of vulnerability induced by climate variability and change is crucial to enhancing livelihood resilience. Vulnerability arising from climate change is often in a continuous state of flux; both the biophysical and social processes that shape local conditions and the ability to cope are themselves dynamic (O'Brien et al. 2005). Carter et al. (2007) state that "vulnerability is the degree to which a system is susceptible to, or unable to cope with, adverse effects of climate change, including climate variability and extremes".

\subsection{Climate change vulnerability assessments in practice}

Global environmental change demands indicator-based analyses of vulnerability in policy circles for identifying, ranking, or distinguishing between units of analysis for informing resource allocation or for targeting support programmes and other interventions (Eakin and Bojorequez-Tapia 2008). In recent years, indicator and metrics based analysis has been used to link system dynamics quantitatively across scales and sectors (Moss et al. 2001; Luers et al. 2003; O’Brien et al. 2004; Brooks et al. 2005; Vincent 2007; Eakin and Bojorequez-Tapia 2008; Hahn et al. 2009). These indicators do not, however, address the dynamic nature of vulnerability in its manifestation and causes adequately (Leichenko and O'Brien 2002; Vogel and O'Brien 2004; Eakin and Luers 2006). Such indices are limited in their application due to high subjectivity in the selection of variables and their relative weights, unavailability of data at various scales, and difficulties concerning testing and validating different metrics (Luers et al. 2003).

Existing vulnerability analysis views climate-human-environment interactions as rigid, linear, and/ or hierarchical giving rise to a general attribution of vulnerability. Although these indicator-based vulnerability assessments are able to capture some interactions between the climate-human-environment systems, they do not adequately capture the dynamics and functions of interconnected systems. The concept of 'interconnectedness' is pivotal in understanding the functioning of a dynamic system. Therefore, it is imperative that an understanding of interconnected relationships in an interaction space be captured and analysed while assessing vulnerability. Vulnerability assessments capable of capturing complex interactions in a system need to be identified against a set of indicators - gauging vulnerability as an outcome of various interconnected factors.

Studies have been increasingly documenting local knowledge vis-à-vis climate variability and change, its impacts, and locally developed knowledge and practices concerning resource use (Hennessey et al. 2007; Leonard et al. 2013). Peoples' perceptions relevant to climate change impact and adaptations are being discussed across governments, intergovernmental and non-governmental organisations throughout the world today (Petheram et al. 2010; Leonard et al. 2013). Constructing a perception-based vulnerability index from a stakeholder perspective is paramount for effective evidence-based decision-making in climate change policy circles and may also prove effective in capturing and analysing complex interconnected interactions. The approach of this study differs from others as it constructs a livelihood vulnerability index to climate variability and change subsuming interconnected relationships 
occurring within the dynamic climate-human-environment interaction space based on people's perceptions. This has been elaborated with the help of sustainable livelihood framework.

This paper is a methodological contribution as it constructs a livelihood vulnerability index to climate variability and change based on peoples' perceptions and their belief systems. It provides an overview of the fuzzy cognitive mapping (FCM) approach and details the processes of data collection and analysis. It also demonstrates the capturing and analysis of sensitivity and adaptive capacities while constructing the livelihood vulnerability index. In the final section, an outline of our research findings is made available through a case study of the Bhilwara district in Rajasthan. There is also a brief discussion on the strengths and limits and the larger policy implications of the livelihood vulnerability index to climate variability and change.

\section{Area of study}

The livelihood vulnerability index to climate variability and change was piloted in the Bhilwara district of Rajasthan, a semi-arid region of Western India. This is the $12^{\text {th }}$ largest district of Rajasthan with a population of 2.41 million and a population density of 230 persons/ $\mathrm{km}^{2}$ (Census of India 2011). Bhilwara ranks $15^{\text {th }}$ among 33 districts in the human development index (0.633) (Directorate of Economics and Statistics 2008) with around $64 \%$ of its entire population engaged in agriculture, particularly crop cultivation and livestock rearing. The net irrigated area to net sown area is $30.25 \%$ (Census of India 2011). Data collection was conducted in nine villages of the district namely, Amartiya, Bagjana, Barundani, Chitamba, Gatuna ka Jhopra, Jalim ka Jhopra, Kartha, Kerakheda, and Sanjadi ka Badiya. Of the 38 groups facilitated for drawing cognitive maps, 17 constituted of women exclusively. Women's groups were represented in every village except for Bagjana and Chitamba.

\section{Methodology}

\subsection{The fuzzy cognitive mapping approach}

The FCM approach, a powerful tool in environmental decision-making and management, attempts to capture the functioning of a complex system based on people's understanding and their belief systems. FCMs use fuzzy-graph structures that represent causal reasoning allowing for systematic causal propagation, particularly forward and backward chaining (Kosko 1986). FCMs consist of a set of nodes representing variables connected through links denoted by arrows (Harary et al. 1965; Özesmi and Özesmi 2004). Each variable represents characteristics of a system while interconnections between the variables depict the dynamics of the system (Papageorgiou and Kontogianni 2012). The variables could be physical, measurable entities and qualitative, aggregate or abstract ideas including ethical, political or aesthetic issues (Reckien et al. 2010). Relationships between these variables are labelled with positive or negative polarities. These polarities describe the arrangement of the system with the positive sign indicating a direct relationship and the negative sign an inverse one. Weights delineating the strength between variables, have been assigned values ranging between 0 and 1 (Özesmi and Özesmi 2004; Reckien et al. 2010). FCM depicts interconnected relationships between variables and explains complex interactions occurring within a dynamic system.

The FCM approach in this study has been deployed to understand the effects of various climate-related perturbations on social, economic, and ecological systems along with 
adaptations that provide resilience against shocks. FCMs are useful tools for modeling complex relationships between variables. FCMs enable the analysis of both direct and indirect feedback aiding the exploration of dynamic vulnerabilities induced by climate variability and change, yielding semi-quantitative results. This is, unlike other approaches as it does not require large datasets that are costly and often unavailable. Local knowledge renders FCMs valuable in the context of supplementing and complementing scientific data, particularly where human behaviour needs to be understood and problems are complex, where many parties are involved and no straight-forward solution is deducible (Reckien et al. 2010; Papageorgiou and Kontogianni 2012). FCMs minimise the possibility of under-identification as illimitable variables and loops can be added that are not well-defined (Özesmi and Özesmi 2004) and may be created by anyone. Similar results may be obtained with smaller samples, which is not the case with other sampling techniques (Özesmi and Özesmi 2004).

Recent studies indicate the potential of fuzzy cognitive mapping in terms of investigating the role of feedback mechanisms in coupled climate-human-environment systems (Reckien et al. 2010; Murungweni et al. 2011). Detailed descriptions of the approach and its application may be found in Özesmi and Özesmi (2004); Isak et al. (2009) and Papageorgiou and Kontogianni (2012). We adopted a partial multi-step FCM approach, suggested by Özesmi and Özesmi 2004 (2004), for collecting data required for the livelihood vulnerability index to climate variability and change. The FCM process involves five steps set out in detail between sections 3.1.1 and 3.1.5.

\subsubsection{Obtaining cognitive maps from communities}

Marginal agro-pastoral communities, the most affected by climate variability and change, were selected for the study. The construction of an FCM was demonstrated to community participants citing an example of extreme heat waves and their direct and indirect impacts along with coping mechanisms providing resilience. Thereafter, the following questions were asked of the participants:

i. What changes in climate have been observed in the past 6 years during the summer, winter, and rainy seasons?

Answers to this question helped us understand peoples' perception of changes occurring in summer and winter temperatures along with precipitation patterns over the past six years while allowing us to capture our central variables. Most perception based studies resort to a 6-20 year recall window for analysing climate variability and change (Diggs 1991; Deressa et al. 2008; Hahn et al. 2009). For this study a 6-year recall window was chosen to capture peoples' perceptions of climate perturbations and adaptations to climate variability and change having realised the respondents' probable inability to accurately report events that gradually alter their lives.

Farmers with land holdings of less than 0.3 ha and a few cattle were selected as community participants/ interviewees. A near consensus on temperature changes observed during summer and winter was achieved and precipitation patterns were established by the participants, who were then divided into 4-5 member groups. In order to avoid the influence of certain members, the participants were divided into homogenous groups based on land holding and gender. Each group was given large sheets of paper; each of the three climate variables was placed as a central variable on a separate sheet. Groups were asked to draw causal relationships concerning direct and indirect climate related perturbations on livelihoods with each central variable based on the following open-ended questions: 
ii. How have your livelihoods been affected due to perceived changes in summer and winter temperatures and rainfall patterns in the last six years?

iii. What are the consequential impacts arising from direct impacts due to changes in climate?

The participant groups listed variables affected by each central climate variable. The groups were then asked to explain the relationships between the variables. These variables were placed around the central variable and links/ interconnections were established between them. Arrows were drawn to indicate the directionality of relationships. After the climate-related perturbations were captured, the groups identified coping strategies and adaptations. The exercise was based on the following open-ended questions:

iv. What are coping mechanisms used to respond to these impacts?

v. Do these coping strategies increase the sensitivity of already occurring climate perturbations?

The groups identified coping mechanisms and adaptation practices and added them to their list of variables. Members of various groups then placed the new variables on the map before linking their relationships in the context of reducing impacts and/or increasing sensitivities.

Once the cognitive maps of climate induced perturbations and coping mechanisms had been drawn up and causal relationships established between variables, relative weights were assigned to these links. These weights were assigned by group participants based on their understanding of the influence of one variable over another. Weights were assigned values ranging between 0 and 10, with 10 representing the highest influence and 0 no influence; this was later scaled down to $0-1$ by the researchers. Positive and negative polarities between the links were provided by the researchers as groups found it difficult to assign signs. A positive sign depicted positive causal relations and a negative sign an inverse relation. In order to reduce biases, including the influence of certain members, the maps were refined with the help of community participants and experts.

\subsubsection{Transforming cognitive maps into a social cognitive map}

Each fuzzy cognitive map may be mathematically represented through adjacency matrices as A (D) $=\left[\mathrm{a}_{\mathrm{ij}}\right]$ (Harary et al. 1965; Özesmi and Özesmi 2004; Reckien et al. 2010) where variable $\mathrm{v}_{\mathrm{i}}$ is listed in the vertical axis and the variables $\mathrm{v}_{\mathrm{j}}$ in the horizontal axis to form a square matrix. When a connection exists, a value between -1 and 1 is coded into the square matrix. Each individual cognitive map is coded into an augmented matrix that includes all variables of the individual cognitive maps. Then all the individual maps are added with the help of matrix addition and normalised to create a social cognitive map in the range of -1 and +1 . The addition of augmented matrices is based on the equivalence properties of fuzzy causal relationships between variables (Özesmi and Özesmi 2004).

\subsubsection{Determining adequacy of samples}

Monte Carlo simulation technique with STATA was deployed to determine sample size through accumulation curves. The average accumulation curve is the total number of maps versus the number of new variables added per map that depicts the adequacy of the sample size based on the way accumulation curve saturates. The average accumulation curve stabilised at 
32 maps. FCMs were created with different groups till the representative population was sampled sufficiently. A total of 38 cognitive maps were obtained during the summer and monsoon seasons while 32 cognitive maps were obtained during the winter season.

\subsubsection{Simplifying/ condensing cognitive maps}

The method employed for condensation was qualitative aggregation enabling the category-wise combination of variables represented by a larger encompassing variable (Özesmi and Özesmi 2004). Condensation entails combining variables with similar characteristics and/ or attributes into a larger category in line with the sustainable livelihood framework.

\subsubsection{Visualising condensed social cognitive map}

FCMs are graphically represented through cognitive interpretive diagrams (CIDs) (Özesmi and Özesmi 2004) for the easy depiction of interconnected interactions occurring within the climate-human-environment system. The size of each node (bubble/ shape) in the CID represents the centrality or the importance of that particular variable in the entire structure of the cognitive map; which means that larger the node size the greater its importance. FCM aids the visualisation of interrelated variables affecting one another while representing feedback.

\subsection{Combining sustainable livelihood (SL) framework with FCM approach}

Climate variability and change adds complexity to livelihood vulnerability analysis. Several studies have incorporated the SL approach for assessing vulnerability (Vasquez-Leon et al. 2003; Eakin and Bojorequez-Tapia 2008; Li et al. 2013; Gautam et al. 2013). The SL framework helps identify the sensitivity of assets, entitlements, and critical assets for coping with and adapting to risks while linking livelihood strategies to opportunities and constraints of the broader institutional and biophysical environment (Kelly and Adger 2000; Eakin and Luers 2006). The SL framework proposed by Chambers and Conway (1992), Scoons (1998), and the Department for International Development (1999) looks at five types of household assets. Another asset - the organisational asset-was incorporated rendering the sustainable livelihood framework more comprehensive. The variables (climate-related perturbations and coping mechanisms) captured by the cognitive maps were categorised under various assets of the SL framework by researchers and refined by experts. This was done to showcase assets providing resilience against perturbations and those sensitive to a particular shock.

\subsection{Constructing the livelihood vulnerability index to climate variability and change}

Vulnerability, according to Adger (2006), includes exposure and sensitivity to perturbations or external stress and adaptive capacity. Exposure according to Fankhauser et al. (2001) is the nature and degree to which a system is exposed to significant climatic variations and sensitivity, is the degree to which a system is affected directly or indirectly, either adversely or beneficially, by climate-related stimuli, directly and/or indirectly. Adaptive capacity is defined here as the ability of a system to manage sensitivity to climatic influences. 


\subsubsection{Calculating climate exposure}

In order to avoid the influence of interviewers' knowledge on community participants, exposure was calculated after data collection. Climate exposure causing perturbations to livelihood security includes changes in summer (April, May and June) and winter (December, January, February) temperatures and precipitation patterns during the rainfall months (July, August and September). Exposure was calculated based on 20 years' daily data (1993-2012). Temperature data was based on Indian Meteorological Department (IMD) and Global Forecast System while rainfall data was derived from IMD and Tropical Rainfall Measurement Mission. Exposure was calculated for each season using Eq. (1).

$$
E_{s}=\left(O_{s}-O_{\min }\right) /_{\left(O_{\max }-O_{\min }\right)}
$$

where, $E_{s}$ is the exposure of each season, $O_{s}$ the 90 -day moving point averages of increase in temperature and decline in rainfall during the latest year recorded. $O_{\min }$ is the minimum value and $O_{\max }$ is the maximum value during the observation period.

\subsubsection{Calculating sensitivity and adaptive capacity}

As mentioned earlier the FCM approach was combined with the modified SL framework for gaining an insight into sensitive assets and those serving as adaptive capacities. FCMs from community participants provided variables indicating sensitivity to climate variability and change as well as variables serving as adaptive capacities. Calculating vulnerability is a complex process in an interaction space with interconnected variables. While calculating the sensitivity of a certain variable every corresponding variable causing its sensitivity is accounted for. Each variable that reduces the sensitivity of variables is included in the analysis of adaptive capacity. Another important interaction includes adaptation practices that increase sensitivity, which is also considered under sensitivity analysis. Sensitivity and adaptive capacity analysis are conducted separately using a weighted balance approach (Sullivan 2002) in which each sub-component contributes to the overall index equally albeit with a varying number of sub-components. For sensitivity analysis, the sensitivity of each variable was calculated first using simple averages as shown in Eq. (2).

$$
S_{v_{i}}=\frac{1}{n} \sum_{x=1}^{n} D_{i_{x}}
$$

Here $S_{v_{i}}$ is the average sensitivity of the $\mathrm{i}^{\text {th }}$ variable, $D_{i}$ are the drivers of sensitivity of the $\mathrm{i}^{\text {th }}$ variable, and $n$ is the number of drivers of each variable $\left(S_{v_{i}}\right)$ causing sensitivity. Once the sensitivity of each variable was obtained, the sensitivity of each asset was calculated using balanced weighted averages as shown in Eq. (3).

$$
A C_{j}=\sum_{i=1}^{i=m} N D_{i} S_{v_{i j}} / \sum N D
$$

Here $A C_{j}$ is the sensitivity of the $\mathrm{j}^{\text {th }}$ asset, $S_{v_{i j}}$ the average sensitivity of the $\mathrm{i}^{\text {th }}$ variable in the $\mathrm{j}^{\text {th }}$ asset; $N D_{i}$ is the number of drivers of the $\mathrm{i}^{\text {th }}$ sensitivity variable and 
$m$ the number of variables in the $\mathrm{j}^{\text {th }}$ asset. Finally, the overall sensitivity was calculated using Eq. (4).

$$
O S_{S}=\sum_{i=1}^{i=n} N V_{j} A C_{j} / \sum N V
$$

Here $O S_{s}$ is the overall sensitivity for each season, $A C_{j}$ the average sensitivity of the $\mathrm{j}^{\text {th }}$ asset, $N V_{j}$ the number of variables in the $\mathrm{j}^{\text {th }}$ asset, and $n$ the number of assets.

Similarly, the adaptive capacity of each variable was calculated using Eq. (5)

$$
A_{v_{i}}=\frac{1}{n} \sum_{x=1}^{n} I R_{i_{x}}
$$

where $A_{v_{i}}$ is the average adaptive capacity of the $\mathrm{i}^{\text {th }}$ variable, $I R_{i}$ the influence of resilience by the $\mathrm{i}^{\text {th }}$ variable, and $n$ the number of variables influenced by each variable $\left(A_{v_{i}}\right)$ that increases resilience. Once the adaptive capacity of each variable is obtained the adaptive capacity of each asset is calculated using balanced weighted averages as shown in Eq. (6).

$$
A C_{x}=\sum_{i=1}^{i=m} N D_{i} A_{v_{i x}} / \sum N D
$$

Here, $A C_{x}$ is the adaptive capacity of the $\mathrm{x}^{\text {th }}$ asset, $A_{v_{i x}}$ the average adaptive capacity of the $i^{\text {th }}$ variable in the $\mathrm{x}^{\text {th }}$ asset, $N D_{i}$ the number of influenced variables by the $i^{\text {th }}$ adaptive capacity variable, and $m$ the number of variables in the $\mathrm{x}^{\text {th }}$ asset. Finally, the overall adaptive capacity was calculated using Eq. (7)

$$
O A C_{s}=\sum_{i=1}^{i=m} N V_{x} A C_{x} / \sum N V
$$

where $O A C_{S}$ is the overall adaptive capacity for each season, $A C_{x}$ the average adaptive capacity of the $\mathrm{x}^{\text {th }}$ asset, $N V_{x}$ the number of variables in the $\mathrm{x}^{\text {th }}$ asset, and $n$ the number of assets.

\subsubsection{Calculating livelihood vulnerability to climate variability and change}

Having calculated exposure, sensitivity, and adaptive capacity the livelihood vulnerability to climate variability and change was calculated for each season using Eq. (8).

$$
L V I_{C C}=E_{s}\left(O S_{s}-O A C_{s}\right)
$$

Here $L V I_{C C}$ is the livelihood vulnerability index to climate variability and change for each season, $E_{s}$ exposure, $O S_{S}$ the overall sensitivity, and $O A C_{S}$ the overall adaptive capacity calculated for each season. It is assumed that as exposure increases the need to adapt will increase, adaptation being a process for existence. Thus, adaptive capacity is subtracted from sensitivity and multiplied by exposure. The $L V I_{C C}$ lies in the range of -1 to 1 ; here -1 represents the least vulnerable, 0 vulnerable, and +1 the most vulnerable. 


\section{Results and discussions}

\subsection{Perception of climate-related perturbations and adaptive mechanisms}

Agro-pastoralists in Bhilwara, acknowledging the inexorability of climate variability and change, have witnessed an increase in summer and winter temperatures and a decline in precipitation. Climate-related perturbations (direct and indirect) on livelihoods due to increased summer and winter temperatures and declining rainfall exert an influence on financial, natural and human assets (Table 1). The direct and indirect impact of these changes in climate are most evident on financial reserves, agricultural produce, fodder, and land followed by human health, water resources, and livestock health (Figs. 1, 2 and 3). Communities have witnessed increasing temperatures and decreasing rainfall directly affecting agriculture, fodder and land, water, and forest resources.

Degrading land and water resources has affected forests and agriculture leading to reduced fuel wood and fodder availability while limiting water resource management strategies (Figs. 1, 2 and 3). Increasing temperatures, declining rainfall, and degrading forests have all aggravated climatic changes involving heat waves and erratic rainfall. Forest degradation continues to deteriorate land resources while augmenting the conflict between humans and wildlife. This, in turn, continues to affect human health. A major contribution to deteriorating human health comes from the combined effect of increase in temperatures, insects and pests, climatic changes and decline in rainfall, water, agricultural and fodder produce. Factors such as declining water and fodder availability coupled with increasing temperatures has been causing livestock health and milk produce to deteriorate leading to adverse effects on human health (Figs. 1, 2 and 3). The decline in agriculture and fodder, along with human and livestock health, has caused financial reserves to deplete and impact education while limiting livelihood diversification opportunities and access to micro-finance (Figs. 1, 2 and 3). Women respondents have emphasised that an increasing frequency of heat waves has amplified stress related to women's health (dehydration) and work efficiency.

Organisational, financial, and social assets provide the system with the ability to manage climate variability and change (Table 1). Organisational assets have facilitated adaptation via setting up watersheds, afforestation, and pastureland development committees. Pastureland development committees have increased fodder availability by enabling institutional arrangements to regulate grazing and fodder collection from common pasturelands. Village-level forest committees facilitate afforestation activities while other groups deal with forest

Table 1 Assets sensitive to climate variability and change and those serving as adaptive capacities

\begin{tabular}{|c|c|c|c|c|c|c|}
\hline \multirow[t]{2}{*}{ Livelihood asset class } & \multicolumn{2}{|c|}{$\begin{array}{l}\text { Increased summer } \\
\text { temperature }\end{array}$} & \multicolumn{2}{|c|}{ Increased winter temperature } & \multicolumn{2}{|c|}{ Decreased Rainfall } \\
\hline & Sensitivity & $\begin{array}{l}\text { Adaptive } \\
\text { capacity }\end{array}$ & Sensitivity & $\begin{array}{l}\text { Adaptive } \\
\text { capacity }\end{array}$ & Sensitivity & $\begin{array}{l}\text { Adaptive } \\
\text { capacity }\end{array}$ \\
\hline Natural & 0.69 & 0.00 & 0.69 & 0.00 & 0.77 & 0.00 \\
\hline Human & 0.65 & 0.61 & 0.72 & 0.47 & 0.66 & 0.53 \\
\hline Physical & 0.68 & 0.60 & 0.65 & 0.59 & 0.57 & 0.62 \\
\hline Financial & 0.74 & 0.63 & 0.80 & 0.81 & 0.76 & 0.67 \\
\hline Social & 0.00 & 0.55 & 0.00 & 0.80 & 0.00 & 0.75 \\
\hline Organisational & 0.00 & 0.77 & 0.00 & 0.68 & 0.00 & 0.70 \\
\hline
\end{tabular}




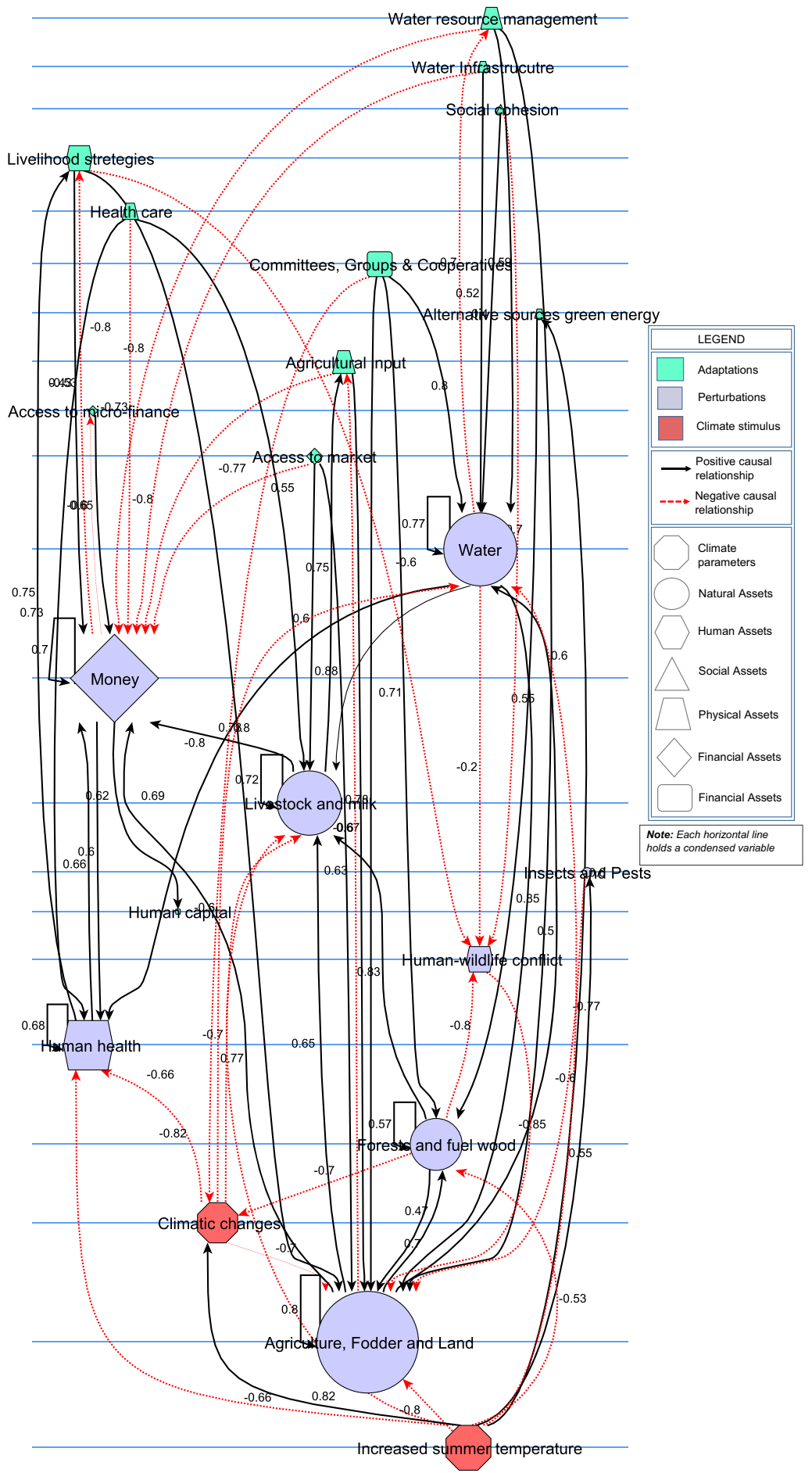

Fig. 1 Perception of impacts and adaptations due to increased summer temperature 


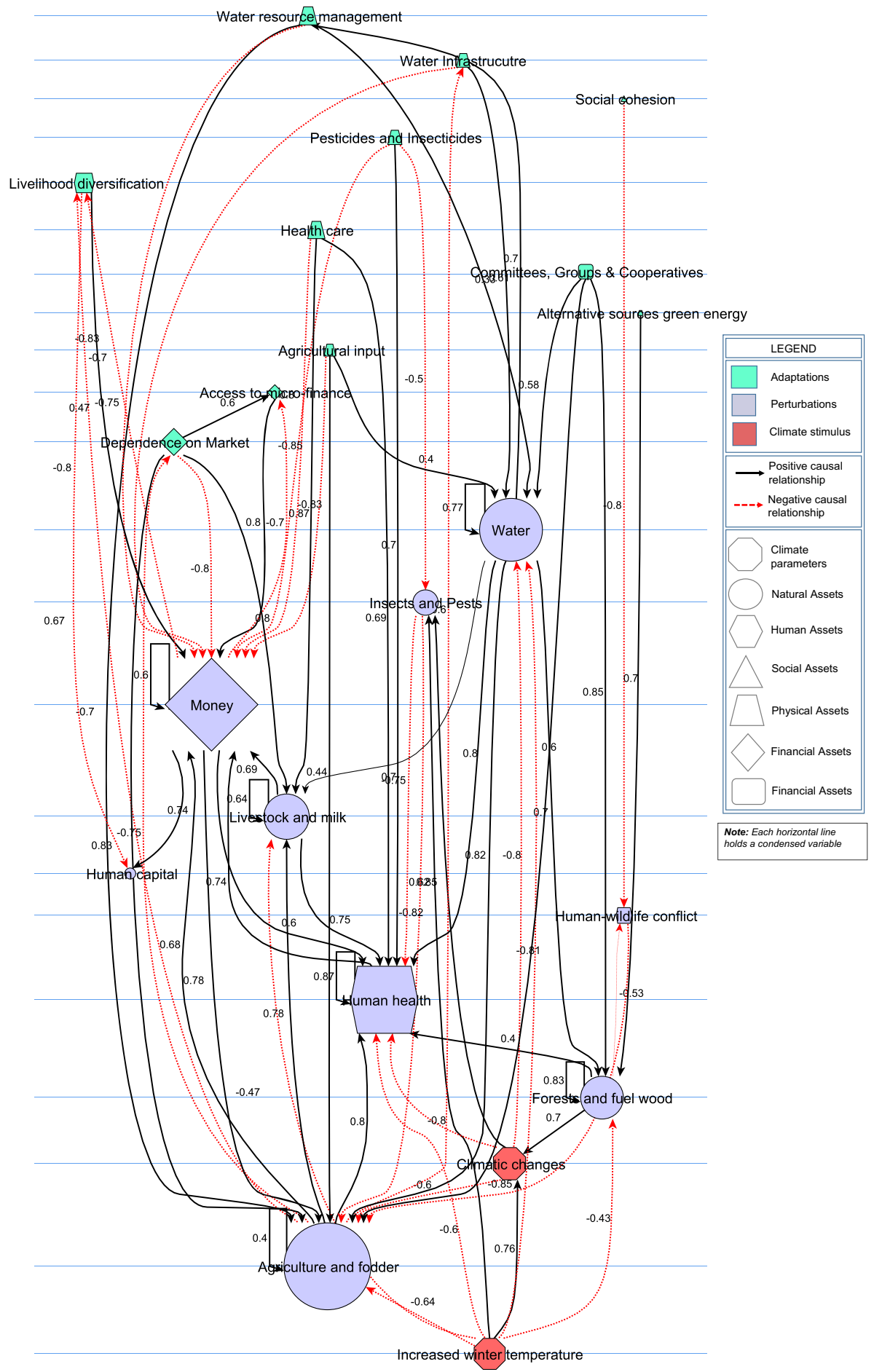

Fig. 2 Perception of impacts and adaptations due to increased winter temperature 

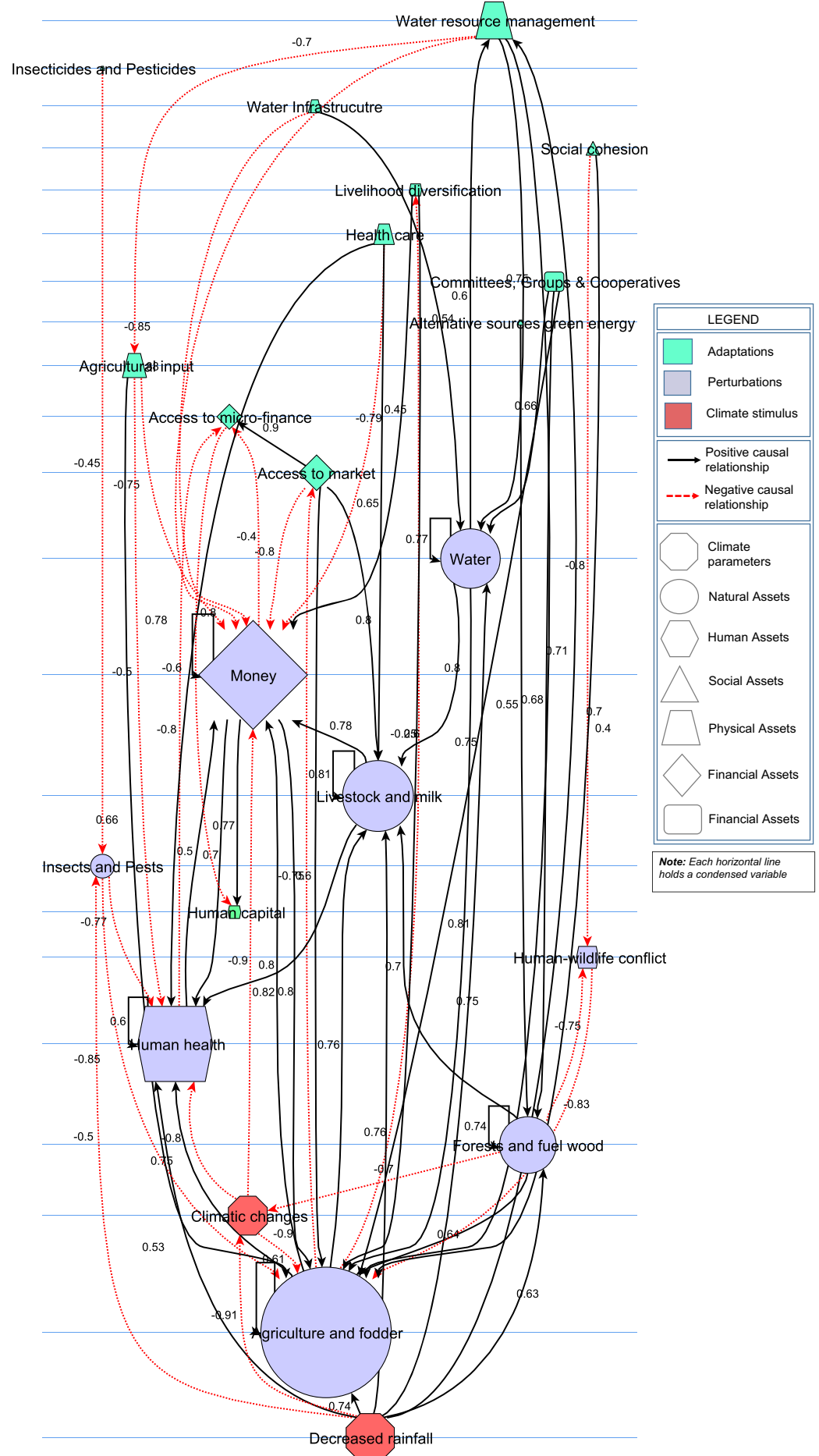

Fig. 3 Perception of impacts and adaptations due to declining rainfall 
protection to enhance forest ecosystem services leading to improved fuel wood availability. Watershed development committees have brought community members together to facilitate the construction of check-dams, loose boulder check-dams and anikets (water supply drains) while raising awareness on water conservation strategies. All these strategies have contributed towards improving land and water resources. Overall committees, groups and cooperatives have contributed towards improving agriculture, fodder, land, forests, fuel wood and water resources while reducing the impacts of climate variability and change (Figs. 1, 2 and 3). These improvements have indirectly led to improved financial reserves.

Financial assets including access to credit have enhanced the adaptive capacity of communities across all seasons. Access to micro-finance has helped communities cope during times of need by providing means of credit and helping improve financial reserves. Market systems also provide alternatives vis-à-vis procurement of food and fodder which has become more frequent due to climate variability and change. This contributes to depleting financial reserves since food and fodder have to be purchased, which would not have been the case if there were no implications of anthropogenic climate change (Figs. 1, 2 and 3). Social assets in the form of social cohesion play an important role in reducing the indirect impacts of climate variability and change including human-wildlife conflict, which has been on the rise due to degrading forests. Social cohesion also helps manage water resources through a system of bhaichara (brotherhood) (Figs. 1, 2 and 3). Physical assets including agricultural inputs, water resource management practices, water infrastructure, health care facilities and alternative sources of green energy contribute towards improving water, agriculture, fodder, land, fuel wood, human and livestock health (Figs. 1, 2 and 3). However, agricultural inputs are perceived as ineffectual vis-à-vis the above-mentioned strategies.

\subsection{Livelihood vulnerability to climate variability and change}

Livelihood vulnerability was calculated over three seasons: summer, winter, and rainfall. It must be borne in mind that vulnerability is not constant and varies across seasons. Figure 4 shows the contributing factors influencing vulnerability relevant to the three seasons in Bhilwara. Livelihood vulnerability due to increased summer and winter temperatures is 0.05 and 0.03 respectively and due to decreasing rainfall is 0.01 . Therefore, livelihood vulnerability of agro-pastoralists in Bhilwara is the highest due to increasing summer temperature.

The data reveal exposure being higher during summer and winter due to increasing temperatures. The exposure component of decreased rainfall is lower than increased temperatures in the study area, which exists in the semi-arid region. The perception of perturbations arising out of increased summer and winter temperatures and decreased rainfall (during the rainfall months) is relatively high. Adaptation practices are high during rainfall months, which are crucial to agro-pastoralists in terms of sustaining livelihoods. The smallest decline in rainfall is said to cause relatively large perturbations.

\subsection{Strengths and limitations to the approach}

The $L V I_{C C}$ has been designed to provide development organisations, policy-makers, and practitioners with a practical tool to understand various livelihood assets contributing towards climate vulnerability. The index is scale-independent helping development planners refine and 


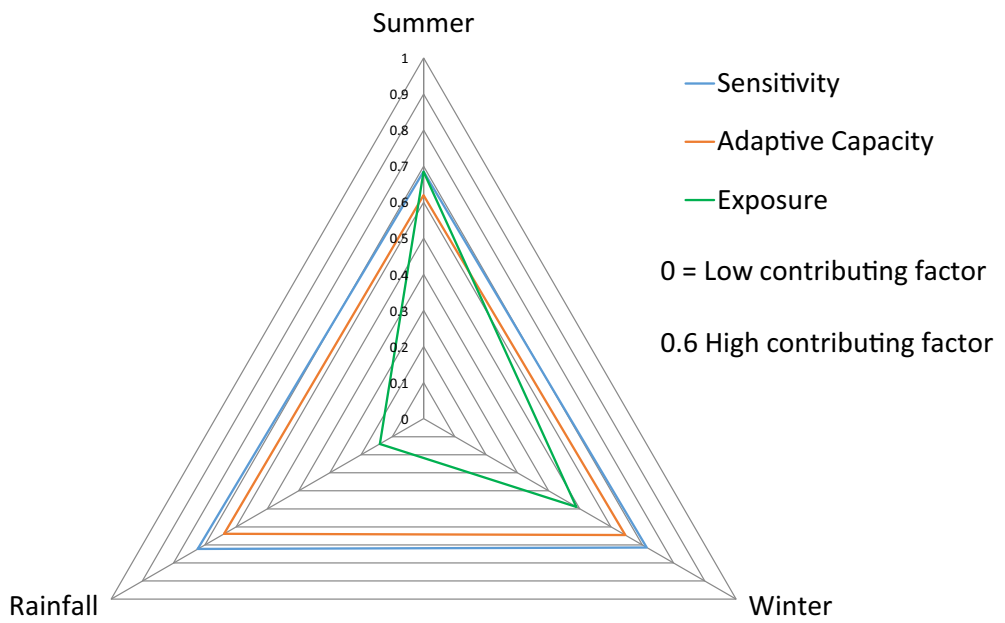

Fig. 4 Contributing factors of the livelihood vulnerability index to climate variability and change

focus their analyses to suit the needs of a geographic unit. Apart from the overall index, sectoral vulnerability scores may be segregated to identify potential areas of intervention. The chief strength of this method is its ability to deal with co-occurrences of multiple causes. This vulnerability assessment is an improvement from other indicator-based assessments given its ability to capture interconnected interactions (cause-effect relationships) occurring within the dynamic climate-human-environment system based on the tacit and explicit knowledge of stakeholders while avoiding subjectivity surfacing during indicator selection. This vulnerability assessment may be conducted on a larger scale, not necessarily at the household-level, warranting ease while comprehending peoples' perspective of vulnerability.

Among the few drawbacks of this method is its inability to provide real-value parameter estimations hence not yielding inferential statistical results. Besides, participants' knowledge, ignorance, misconceptions and biases are all encoded in the maps; these are partially overcome by augmenting individual cognitive maps (Özesmi and Özesmi 2004). The assignment of directionality from less to more vulnerable is also based on normative judgments. This vulnerability analysis depicts interconnected pathways existing within an interaction space along with multiple causes that could enhance or reduce vulnerability while addressing concerns in global environmental change research necessitating indicator-based vulnerability analysis that captures complex dynamics.

\subsection{Policy implications}

This livelihood vulnerability assessment allows for the depiction of peoples' perspectives by constructing their mental models through the FCM approach. Stakeholders' perceptions being crucial to development planning, this index helps decision makers access indicators for resource allocation and prioritise development-related activities incorporating stakeholders' perspectives. Policy implications derived from this approach come with advantages as stakeholders explain climate change impacts that they have witnessed. The approach also helps explain adaptations that have been effective in reducing sensitivities. Combining the FCM approach with the sustainable 
livelihood framework enables the assessment of assets crucial to sustaining livelihoods. It also explains the assets impacted and those serving as coping mechanisms for livelihood security.

Climate variability and change has always affected the poor first. It is evident from our findings that marginal farmers perceive climate variability and change as leading to further impoverishment in semi-arid Bhilwara. Communities believe that climate variability and change indirectly affects their financial reserves by deteriorating their natural assets. Their main concerns include declining agriculture and fodder, degrading land water and forest resources, and impacting livestock and human health. It is imperative that national and sub-national governments arm communities in the semiarid regions of India with the means and opportunities leading to enhancing resilience of their natural assets that are directly impacted by climate variability and change. Organisational assets have played a crucial role in protecting and enhancing ecosystem services by setting up afforestation, pastureland, and watershed development committees. Strengthening and improving such programmes by demonstrating, for instance, climate smart agricultural practices to communities and mainstreaming climate resilient agricultural practices into policy processes through conscientisation and social dialoguing may prove effective in combating climate change. Social cohesion plays an important role in water management in the form of bhaichara in Bhilwara. Conscientisation of communities regarding adopting a system of bhaichara in semiarid regions will help reduce conflicts, increase cooperation while managing resources, and enhance natural assets. It may be observed that dependence on the market is not viable as it depletes financial reserves. Furthermore, climate variability and change has deteriorated human and livestock health along with milk produce. Though these are considered secondary impacts serving to increase the vulnerability of livelihoods, it is important that national and sub-national governments work towards enhancing the resilience of agricultural practices while simultaneously providing civic amenities that reduce vulnerabilities of communities. Examples include access to low-cost health care and the construction of climate smart cattle-sheds that protect livestock from heatstress and increase milk production thereby. These practices could help communities along with national and sub-national governments move towards a climate resilient development pathway in the semi-arid regions of India.

\section{Conclusions}

Crucial to grasping vulnerability is capturing interconnected relationships occurring in an interacting space like the dynamic climate-human-environment system. These interconnected relationships portray dynamic vulnerability as opposed to linear indicator-based vulnerability assessments describing an interacting space without showcasing interconnected relationships. The FCM-based livelihood vulnerability index to climate variability and change depicts peoples' understanding on how sensitive they are to climate variability and change and how they respond to it. It yields relative values that act as the representation of a belief system while providing relative indicators to policy circles. This not only supplements findings in areas lacking scientific data but also helps compare people's perceptions to scientific data while acting as a powerful tool for understanding human behaviour. Such studies can open up new avenues for research including understanding the insecurities of people due to food and water shortages induced by environmental degradation, pollution, and climate change. 
Acknowledgments We are thankful to the Department of Science and Technology, Government of India and the International Development Research Centre, Canada for providing financial support for the study. We thank Ms Sushumna Agarwal for contributing to the development of the livelihood vulnerability index and Ms Indrani Talukdar for language editing. Finally, we would like to thank the editor and the three anonymous reviewers for their insightful comments, which encouraged the improvement of the manuscript.

Open Access This article is distributed under the terms of the Creative Commons Attribution License which permits any use, distribution, and reproduction in any medium, provided the original author(s) and the source are credited.

\section{References}

Adger WN (2006) Vulnerability. Glob Environ Chang 16:268-281. doi:10.1016/j.gloenvcha.2006.02.006

Brooks N, Adger WN, Kelly PM (2005) The determinants of vulnerability and adaptive capacity at the national level and the implications for adaptation. Glob Environ Chang 15:151-163. doi:10.1016/j.gloenvcha.2004. 12.006

Carter TR, Jones RN, Lu X, Bhadwal S, Conde C, Mearns LO, O’Neill BC, Rounsevell MDA, Zurek MB (2007) New assessment methods and the characterisation of future conditions. In: Parry ML, Canziani OF, Palutikof JP, van der Linden PJ, Hanson CE (eds) Climate change 2007: impacts adaptation and vulnerability. Contribution of working group II to the fourth assessment report of the intergovernmental panel on climate change. Cambridge University Press, Cambridge, pp 133-171

Census of India (2011) Population of India, New Delhi: Office of the Registrar General and Census Commissioner, India

Chambers R, Conway G (1992) Sustainable rural livelihoods: Practical concepts for the 21st century. IDS Discussion Paper-296, Institute of Development Studies, Brighton

Department for International Development (1999) Sustainable Livelihoods Guidance Sheets, London

Deressa TR, M Hassan, T Alemu, M Yesuf, C Ringler (2008) Analyzing the Determinants of Farmers' Choice of Adaptation Methods and Perceptions of Climate Change in the Nile Basin of Ethiopia. International Food Policy Research Institute, Discussion Paper 00798

Diggs DM (1991) Drought Experience and Perception of Climatic Change among Great Plains Farmers. Great Plains Research: A Journal of Natural and Social Sciences, Paper-1

Directorate of Economics and Statistics (2008) Bhilwara and Tonk profile. Jaipur: Directorate of Economics and Statistics, Government of Rajasthan [Accessed 3 April 2013]

Eakin H, Bojorequez-Tapia AL (2008) Insights into the composition of household vulnerability from multicriteria decision analysis. Glob Environ Chang 18:112-127. doi:10.1016/j.gloenvcha.2007.09.001

Eakin H, Luers L (2006) Assessing the Vulnerability of Socio-Environmental Systems, Annual Reviews, pp 365-394 doi: 10.1146/annurev.energy.30.050504.144352

Fankhauser S, Leemans R, Erda L, Ogallo L, Pittock B, Richels R, Rosenzweig C, Safriel U, Tol RSJ, Weyant J, Yohe G (2001) In: climate change 2001: impacts adaptation and vulnerability. Contribution of working group II to the third assessment report of the intergovernmental panel on climate change. Cambridge University Press, Cambridge

Gautam MR, Chief K, William JS Jr (2013) Climate change in arid lands and native American socioeconomic vulnerability: the case of the pyramid lake Paiute tribe. Clim Chang 120:585-599. doi:10.1007/s10584-0130737-0

Gopalakrishnan R, Jayaraman M, Ravindranath NH (2011) Regional Climate Modeling results for Rajasthan state. In: Science-based policy options for climate change adaptation in Rajasthan, Jaipur, Rajasthan State Pollution Control Board, Jaipur, India

Hahn M, Riederer N, Foster S (2009) The livelihood vulnerability index: a pragmatic approach to assessing risks from climate variability and change: a case study in Mozambique. Glob Environ Chang 19:74-88. doi:10. 1016/j.gloenvcha.2008.11.002

Harary F, Norman RZ, Cartwright D (1965) Structural models: an introduction to the theory of directed graphs. John Wiley \& Sons, New York

Hennessey K, Fitzharris B, Bates BC, Harvey N, Howden SM, Hughes L (2007) In: climate change 2007: impacts. Adaptation and vulnerability. Contribution of working group II to the third assessment report of the intergovernmental panel on climate change. Cambridge University Press, Cambridge, pp 507-540 
IFAD and the Global Mechanism (2009) Climate change impacts in the Asia/ Pacific Region. In: International Fund for Agricultural Development [Accessed 4 May 2013]

Isak K, Wildenberg M, Adamescu M, Skov F, De Blust G, Varjopuro R (2009) Manual for applying Fuzzy Cognitive Mapping - experiences from ALTER-Net. Alter-Net final report [Accessed 8 May 2013]

Kelly PM, Adger WN (2000) Theory and practice in assessing vulnerability to climate change and facilitating adaptation. Climate Change 47:325-352

Kosko B (1986) Fuzzy cognitive maps. Academic Press Inc Limited. London, International Journal Manmachine Studies 24:65-75 doi: 0020-7373/86/010065+11503.00/0

Leichenko R, O'Brien K (2002) The dynamics of rural vulnerability to global change: the case of southern Africa. Mitig Adapt Strateg Glob Chang 7:1-18

Leonard S, Parsons M, Olawsky K, Kofoda F (2013) The role of culture and traditional knowledge in climate change adaptation: insights from east Kimberley, Australia. Glob Environ Chang 23:623-632. doi:10.1016/j. gloenvcha.2013.02.012

Li Y, Conway D, Wu Y, Gao Q, Rothausen S, Xiong W, Ju H, Lin E (2013) Rural livelihoods and climate variability in Ningxia. Northwest China Clim Chang. doi:10.1007/s10584-013-0765-9

Luers A, Lobell D, Sklar LS, Addams CL, Matson PM (2003) A method for quantifying vulnerability, applied to the Yaqui Valley, Mexico. Glob Environ Chang 13:255-267. doi:10.1016/S0959-3780(03)00054-2

Moss RH, Brenkert AL, Malone EL (2001) Vulnerability to climate change: a quantitative approach. Richland, Washington: Pacific Northwest National Laboratory [Accessed 6 May 2013]

Murungweni C, Wijk MT, Andersson JA, Smaling EMA, Giller KE (2011) Application of fuzzy cognitive mapping in livelihood vulnerability analysis. Ecol Soc 16:8. doi:10.5751/ES-04393-160408

O’Brien KL, Leichenko R, Kelkarc U, Venemad H, Aandahl G, Tompkins H, Javed A, Bhadwal S, Barg S, Nygaard L, West J (2004) Mapping vulnerability to multiple stressors: climate change and globalization in India. Glob Environ Chang 14:303-313. doi:10.1016/j.gloenvcha.2004.01.001

O'Brien KL, Eriksen S, Schjolden A, Nygaard L (2005) What's in a word? Interpretations of vulnerability in climate change research. Oslo. Center Int Clim Environ Res (CICERO) Work Paper 2004:04-16

Olsson L, Opondo M, Tschakert P (2014) Climate change 2014: livelihoods and poverty. Contribution of working group II to the fifth assessment report of the intergovernmental panel on climate change. Cambridge University Press, Cambridge

Özesmi U, Özesmi LO (2004) Ecological models based on people's knowledge: a multi-step fuzzy cognitive mapping approach. Ecol Model 176:43-64. doi:10.1016/j.ecolmodel.2003.10.027

Papageorgiou E, Kontogianni A (2012) Using fuzzy cognitive mapping in environmental decision making and management: a methodological primer and an application. Int Perspect Glob Environ Chang, Ch 21:428450

Petheram L, Zander KK, Campbell BM, High C, Stacey N (2010) Strange changes: indigenous perspectives on climate change and adaptation in NE Arnhem land (Australia). Glob Environ Chang 20:681-692. doi:10. 1016/j.gloenvcha.2010.05.002

Reckien D, Wildenberg M, Deb K (2010) Understanding climate change impacts and adaptation options in developing Countries' Megacities. Resilient Cities: Cities Adapt Clim Chang Proc Glob Forum Ch 3:15-34

Scoons I (1998) Sustainable Rural Livelihoods: A Framework for Analysis. Institute of Development Studies, Brighton (IDSB), Brighton: IDSB. Working paper-72

Sullivan C (2002) Calculating a water poverty index. World Dev 30:1195-1210. doi:10.1016/s0305-750X(02) 00035-9

SDC V\&A Programme (2009) Vulnerability and Adaptation experiences from Rajasthan and Andhra Pradesh. Swiss Agency for Development Cooperation, India

Vasquez-Leon M, West CT, Finan TJ (2003) A comparative assessment of climate vulnerability: agriculture and ranching on both sides of the US-Mexico border. Glob Environ Chang 13:159-173. doi:10.1016/S09593780(03)00034-7

Vincent K (2007) Uncertainty in adaptive capacity and the importance of scale. Glob Environ Chang 17:12-24. doi:10.1016/j.gloencha.2006.11.009

Vogel C, O’Brien KL (2004) Vulnerability and global environmental change: rhetoric and reality. AVISO 13:1-8 